\title{
Kammerflimmern, musikalisch
}

Eberhard Wolff

eberhard-wolff[at]saez.ch
Medienmix liegt im Trend. Fernsehsendungen werden im Internet weiterdiskutiert, und ob man sie jetzt als Unterhaltung oder als Information verbuchen muss, lässt sich ohnehin nicht mehr genau sagen. Auch der traditionelle Liederabend ist nicht mehr das, was er früher einmal war. Die beiden internationalen Schweizer Musikkünstler Markus Schönholzer und Marianne Racine beschreiten mit dem «Weshalb Forellen Quartett» diesen hybriden Weg mit einem ganz speziellen Programm namens «Kammerflimmern»: ein Liebesliederabend, angereichert durch einen populären medizinischen Vortrag aus dem Themenfeld der Liebe. Die Premiere unlängst in Zürich fand dazu sogar noch in der akademisch-klinischen

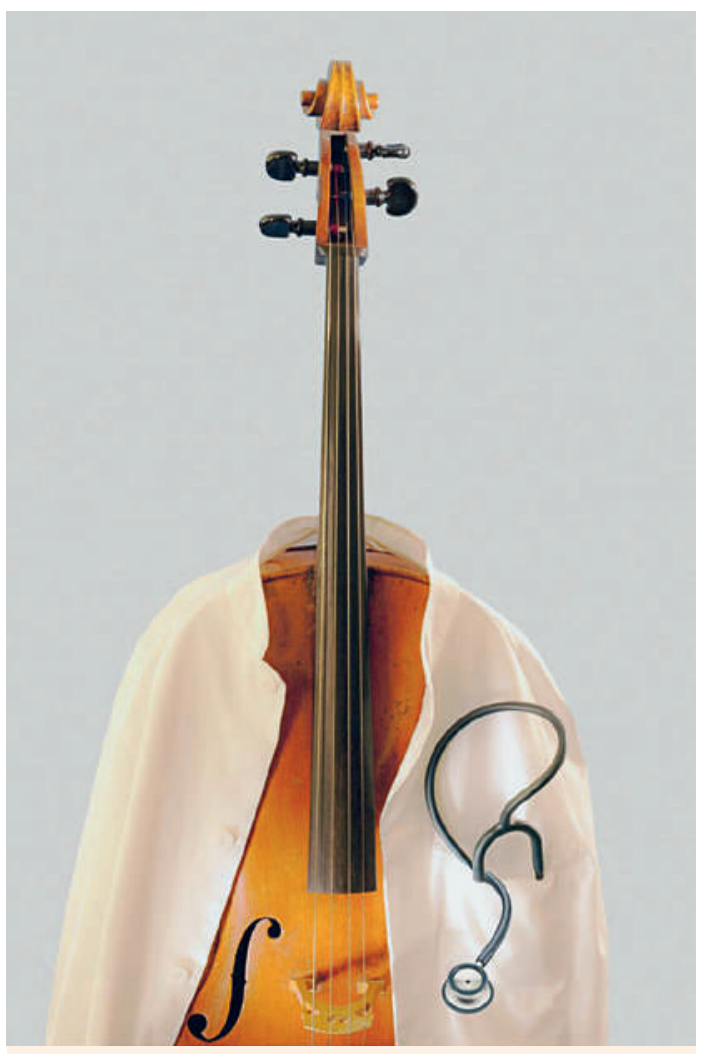

Liebeslieder, vorgetragen von Markus Schönholzer und Marianne Racine, angereichert durch Vortragshäppchen über psychische und physische Auswirkungen der Liebe, vorgetragen von «echten» Medizinern.
Atmosphäre des grossen USZ-Hörsaals Ost statt: harte Hörsaalbänke zu sanften Liebesklängen.

Das Programm erstreckt sich musikalisch von den Everly Brothers über Elvis Costello, Joni Mitchell bis hin zu Volksliedern und Schostakowitschs drittem Streichquartett, notabene betextet. Überhaupt: Die Mundartfassungen aus der Feder des Musicalund Filmkomponisten Markus Schönholzer sind ein besonderer Leckerbissen, ebenso wie die stimmsicheren und ausdrucksstarken Jazzinterpretationen von Marianne Racine sowie die eigenwilligen Streichquartett-Arrangements, die die fehlenden fetten Bläsersätze der Jazztitel mehr als ersetzen.

Medizinisch sind die Auftritte angereichert durch Vortragshäppchen jeweils wechselnder, meist regionaler Mediziner über psychische und physische Auswirkungen der Liebe. Die Fachrichtungen der jeweils vortragenden Ärzte erstrecken sich vom Hirnforscher über den Allgemeinmediziner bis zum Kardiologen.

Ein interessantes und unterhaltsames Experiment. Zuhören empfohlen. (www.markus-schönholzer.ch (mit Hörprobe).

\section{Tourneedaten}

10.5.2013, 20 Uhr, Cinema s'il Plaz, Ilanz

Gastdozent: Dr. med. Uwe Scharf

(Kardiologie und Allgemeinmedizin, Ilanz)

24.5.2013, 20 Uhr, La Marotte, Affoltern am Albis Gastdozent: Dr. med. David Koller (Kardiologie, Herzpraxis am Albis)

31.5.2013 und 1.6.2013, $20 \mathrm{Uhr}$, Theater Ticino, Wädenswil

13.9.2013, 20 Uhr, Sternenkeller, Rüti

16.11.2013, $20 \mathrm{Uhr}$, Somehuus, Sursee

5.10.2013, 20.15 Uhr, Kulturraum, Thalwil Gastdozent: Dr. med. Hansueli Späth, a. A. (Allgemeine Innere Medizin, Langnau )

\subsubsection{4, 20 Uhr, Mühle Otelfingen}

Die Namen der restlichen ärztlichen Referierenden werden noch auf www.markus-schönholzer.ch bekanntgegeben. 